\title{
Faecal elastase 1 levels in premature and full term infants
}

\author{
M Kori, A Maayan-Metzger, R Shamir, L Sirota, G Dinari
}

Arch Dis Child Fetal Neonatal Ed 2003;88:F106-F108

See end of article for authors' affiliations

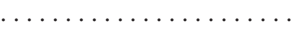

Correspondence to: Dr Dinari, Institute of Pediatric Gastroenterology and Nutrition, Schneider Children's Medical Center of Israel, 14 Kaplan St, Petah Tikva 49202, Israel; dinari@post.tau.ac.il

Accepted 5 August 2002
Background: Determination of faecal elastase 1 (FE 1) is a simple, relatively inexpensive, non-invasive, highly specific and sensitive test for determining pancreatic function. Secretion of pancreatic enzymes varies during infancy, but there are almost no specific data on the ontogeny of elastase 1 in human babies.

Aim: To study FE 1 levels in preterm and term babies, and to determine the possible effect of gestational and postconceptual age on these levels.

Methods: Serial stool samples were collected and tested for FE 1 level from 77 premature and full term infants. FE 1 levels were determined by a commercially available enzyme linked immunosorbent assay (ELISA) kit.

Results: A total of 232 stool samples were collected from 77 neonates. The FE 1 level measured in the first stool sample (meconium) was below normal $(200 \mathrm{\mu g} / \mathrm{g}$ stool) in all samples regardless of gestational age. Sixty three neonates had at least two samples tested for FE 1 level. The mean (SD) level of FE 1 in sample 1 was $45.9(51.1) \mathrm{\mu g} / \mathrm{g}$ stool and was significantly $(\mathrm{p}<0.001)$ lower than in sample 2 (243.0 (164.9) $\mathrm{kg} / \mathrm{g}$ stool). The lower the gestational age of the newborn, the more time it took for FE 1 to reach normal levels.

Conclusions: FE 1 levels in meconium are low, and studies in meconium should be avoided if pancreatic sufficiency is to be determined. FE 1 reaches normal levels by day 3 in term newborns and by 2 weeks in infants born before 28 weeks gestation. Normal levels are reached sooner in infants of more advanced gestational age who start enteral feeding earlier.
$\mathrm{T}$ esting of pancreatic function is a valuable tool in the assessment, diagnosis, overall management, and prognosis of pancreatic disease. The secretin-pancreozymin test is the optimum method for evaluating pancreatic function, but is invasive, time consuming, and costly, so that it is relatively rarely used. There is rarely a real indication for this test, especially in children. ${ }^{1}$ Less invasive tests are therefore usually used. Measurement of pancreatic enzymes, such as trypsin or chymotrypsin, in stool has low sensitivity and specificity. Indirect tests, such as the bentiromide or the pancreolauryl tests, depend on measurement of products of pancreatic digestion in serum or urine, and results are influenced by factors such as gastric emptying, intestinal absorption, and kidney function. Although easy to perform, they are not sensitive enough to diagnose mild to moderate pancreatic insufficiency, and are not suitable for very young infants. Elastase 1 (FEl) is a pancreatic protease, which is stable throughout the intestine, so that FEl level reflects exocrine pancreatic capacity. Recently, FEl determination has proven to be a simple, relatively inexpensive, non-invasive, highly specific and sensitive test for determining pancreatic function ${ }^{2}$ and differentiating severe from milder pancreatic insufficiency. ${ }^{3}$

Despite structural maturity of the pancreas at term, the newborn is known to secrete considerably lower amounts of pancreatic enzymes than older children or adults. Enzyme activity is detectable in human fetal pancreatic tissue from before 20 weeks gestation, and pancreatic secretion begins around the fifth month. Each enzyme appears and develops in an individual manner. ${ }^{4}$ Most studies have shown that, at birth, protease levels are close to normal adult levels, lipase levels are very low, and amylase levels are undetectable..$^{5-10}$

There are no specific data on the ontogeny of elastase 1 in human babies. There are sparse data on FEl levels in preterm and term newborns. The objective of our study was therefore to study FEl levels in term and premature babies, and to determine the possible effect of gestational and postconceptual age on these levels and pancreatic function.

\section{PATIENTS AND METHODS}

Serial stool samples were collected and tested for FEl levels from 77 newborn infants (69 premature and eight full term infants) admitted to the neonatal intensive care unit and nursery at Schneider Children's Medical Center of Israel.

The first stool sample was collected within the first 4 days of birth, and in most cases within 48 hours of birth. Two to four further stool samples were taken twice weekly. All stool samples were stored at $-4^{\circ} \mathrm{C}$ to $-8^{\circ} \mathrm{C}$ until analysis.

Data on gestational age, birth weight, sex, age, weight, and feeding status at each sampling were recorded.

FEl level was determined with a commercially available enzyme linked immunosorbent assay (ELISA) kit (ScheBoTech, Wettenberg, Germany), which uses two monoclonal antibodies against specific epitopes of human pancreatic elastase. According to the manufacturer, FEl concentrations of more than $200 \mu \mathrm{g} / \mathrm{g}$ stool indicate normal pancreatic function, levels of $100-200 \mu \mathrm{g} / \mathrm{g}$ stool indicate mild to moderate pancreatic insufficiency, and severe exocrine pancreatic insufficiency is indicated by levels below $100 \mu \mathrm{g} / \mathrm{g}$ stool. These reference levels only refer to adults.

\section{Statistical analysis}

The analysis was performed using BMDP statistical software. As the data for elastase did not distribute normally, we applied a square root transformation. We used the following statistical tests: Pearson's $\chi^{2}$ test, Pearson's correlation, one way analysis of variance, and analysis of variance with repeated measures.

\section{RESULTS}

A total of 232 stool samples were collected from 77 neonates. The mean (SD) gestational age of the study group was 30.9 (3) weeks (range 23-40). Mean (SD) birth weight was 1535 (701) g (range 490-4170). There were 48 male newborns and 29 female. Five newborns died during the study period. Enteral feeding was started at a mean (SD) age of 3.4 (3.1) days (range 1-13). 
Table 1 Mean fecal elastase 1 levels in sample 1 (meconium) and sample 2 according to gestational age

\begin{tabular}{lrll}
\hline $\begin{array}{l}\text { Gestational } \\
\text { age (weeks) }\end{array}$ & No & Sample 1 & Sample 2 \\
\hline$<28$ & 12 & $28.8(39.6)$ & $139.9(127.2)$ \\
$28-30$ & 7 & $76.7(70.5)$ & $184.8(113.4)$ \\
$31-32$ & 18 & $31.8(31.5)$ & $182.1(128.6)$ \\
$>33$ & 26 & $55.3(57.2)$ & $348.4(160.5)$ \\
All & 63 & $45.9(51.1)$ & $243.0(164.9)$ \\
\hline
\end{tabular}

Results are expressed as mean (SD).

Sixty three newborns had at least two samples of stool available for FEl determination, the first sample of which was meconial, and taken before day 4 (most samples were collected by day 2). FEl level measured in the first, meconial, stool sample was below $200 \mu \mathrm{g} / \mathrm{g}$ stool in all samples regardless of gestational age. The mean (SD) level of FEl in sample 1 was $49.5(51.1) \mu \mathrm{g} / \mathrm{g}$ stool and was significantly $(\mathrm{p}<0.001)$ lower than in sample 2 (243.0 (164.9) $\mu \mathrm{g} / \mathrm{g}$ stool).

When comparing FEl levels in meconium (sample 1) and sample 2 (non-meconial, taken three to seven days later), in different groups according to gestational age, mean FEl levels were above $180 \mu \mathrm{g} / \mathrm{g}$ stool in sample 2 in all age groups except newborns of less than 28 weeks gestation (table 1 ).

To determine the possible effect of meconial factors on FEl levels, 10 meconium samples were mixed with non-meconial stool samples in a 1:1 ratio. FEl levels were determined before and after the mixture. The level of FEl in the mixture was proportional to the level in the non-meconial stool sample, excluding a possible inhibitory effect of meconial factors (data not shown).

We examined the possible correlation between FEl levels and gestational age, birth weight, and the age at which enteral feeding was started. There was a positive correlation between gestational age and FEl level $(r=0.29, \mathrm{p}<0.01)$, and the level of FEl was higher in newborns of more advanced gestational age.

In all full term newborns, the level of FEl in sample 2 was normal. In the whole study group, there were 72 newborns in which FEl eventually reached a normal level. We calculated the age at which the FEl level reached normal values in the preterm infants with serial samples of FEl. Premature infants born at less than 28 weeks gestation reached normal FEl at a mean of 12 days after birth, infants born at 28-32 weeks gestation at 8.4 days, infants born at 32-34 weeks gestation at 5.6 days, and infants born after 34 weeks gestation at 2.8 days. The lower the gestational age, the longer it took FEl to reach normal levels $(r=-0.55, \mathrm{p}<0.001)$. The same was true for birth weight $(r=-0.45, \mathrm{p}<0.001)$.

In the group of infants who eventually reached normal FE 1 levels, a strong negative correlation was found between gestational age and the first enteral feed $(r=-0.65$, $\mathrm{p}<0.001)$. There was a positive correlation between the age at which enteral feeding was started and FEl levels: the later enteral feeding was started, the later FEl reached normal levels $(r=0.5, \mathrm{p}<0.001)$.

\section{DISCUSSION}

Pancreatic elastase 1 is a specific human protease with elastolytic activity, synthesised by pancreatic acinar cells. ${ }^{11}$ Pancreatic elastase is not degraded during intestinal transit and is species specific. FEl levels correlate well with direct tests of pancreatic function. ${ }^{2}{ }^{12}$ Previous studies have shown that, at birth, protease levels are close to adult levels, but there are only a few studies of the specific human protease, elastase 1 , in preterm and term newborns. Nissler et al ${ }^{13}$ measured pancreatic elastase 1 concentration in faeces of 148 infants up to 12 months of age. They found that over $96 \%$ of infants had elastase 1 concentrations greater than an adult lower limit of normal after 2 weeks of life, independent of gestational age and the type of nutrition. Up to 48 hours after birth, $43 \%$ of term infants had normal adult values, whereas none of the preterm infants had elastase 1 concentrations in the normal range.

Von Seebach \& Henker ${ }^{14}$ measured FEl levels in 28 preterm and 27 term newborns. The mean level of FEl in meconium was $63.9 \mu \mathrm{g} / \mathrm{g}$ stool and rose to over $200 \mu \mathrm{g} / \mathrm{g}$ at 1 month of age, independently of gestational age. In another study, FEl levels rose to normal by 2 weeks. ${ }^{15}$

The aim of our study was to measure FEl levels in preterm and term babies, and to determine the possible effect of gestational and postconceptual age on these levels and pancreatic function. Our results show that the level of FEl in meconium is low, compared with the level in stool taken at a later age, regardless of gestational age. The chronological age at which the level of FEl was determined had major importance. FEl levels determined during the first days of life in meconium samples were significantly lower than levels determined later. In full term newborns the second sample taken by day 3-4 was normal. In premature infants, the lower the gestational age of the infant, the longer it took FEl to reach normal levels, but even in the very premature infants, born at 28 weeks gestation or less, FEl reached normal levels by 2 weeks of age. The results of mixing meconium and regular stools excluded the possibility of an inhibitory factor in the meconium.

We also showed that the earlier the newborn starts feeding, the sooner FEl reaches normal levels. This may be related to earlier elastase secretion with feeding or may possibly be due to relative pancreatic insufficiency in very premature sick infants not being fed.

In conclusion, FEl levels in meconium are low and do not indicate pancreatic insufficiency. FEl reaches normal levels by day 3 to 4 in term newborns and by 2 weeks of age in infants born before 28 weeks gestation. FEl reaches normal levels sooner in infants of more advanced gestational age who start enteral feeding earlier.

\section{ACKNOWLEDGEMENTS}

FEl ELISA kits were kindly provided by ScheBoTech GmbH, Wettenberg, Germany.

\section{...................}

\section{Authors' affiliations}

M Kori, R Shamir, G Dinari, Institute of Pediatric Gastroenterology and Nutrition, Schneider Children's Medical Center of Israel, Petah Tikva, Israel

A Maayan-Metzger, L Sirota, Neonatal Intensive Care Unit, Schneider Children's Medical Center of Israel

\section{REFERENCES}

1 Kopelman RH. Pancreatic function testing. In: Wyllie R, Hyams JS, eds. Pediatric gastrointestinal disease. Philadelphia: Saunders, 1993:846-53.

2 Soldan W, Henker J, Sprossig C. Sensitivity and specificity of quantitative determination of pancreatic elastase-1 in feces of children. $J$ Pediatr Gastroenterol Nutr 1997;24:53-5.

3 Gullo L, Graziano L, Babbini S, et al. Faecal elastase-1 in children with cystic fibrosis. Eur J Pediatr 1997;156:770-2.

4 McClean P, Weaver LT. Ontogeny of human pancreatic exocrine function. Arch Dis Child 1993;68:62-5.

5 Werlin SL. Development of the exocrine pancreas. In: Walker AW, Durie PR, Hamilton JR, et al, eds. Pediatric gastrointestinal disease. Philadelphia: Mosby, 1996:143-61.

6 Zoppi G, Andereotti G, Pajno-Ferrara F, et al. Exocrine pancreas function in premature and full term infants. Pediatr Res 1972;6:880-6.

7 Lebenthal E, Lee PC. Development of functional response in human exocrine pancreas. Pediatrics. 1980;66:556-60.

8 Kolack S, Puntis JWL, Lloyd DR, et al. Ontogeny of pancreatic exocrine function. Arch Dis Child 1990;65:178-81. 
9 Fomon SJ, Ziegler EE, Thomas LN, et al. Excretion of fat by normal full term infants fed various milks and formulas. Am J Clin Nutr 1970;23:1299-313

10 Katz L, Hamilton JR. Fat absorption in infants of birth weight less than 1300 gr. J Pediatr 1974;85:608-14.

11 Mallory PS, Travis A. Human pancreatic enzymes: purification and characterization of a nonelastolytic enzyme. J Biochem (Tokyo) 1975; 14:722-30.

12 Loser C, Mollgaard A, Folsch UR. Fecal elastase-1: a novel, highly sensitive, and specific tubeless pancreatic function test. Gut 1996:39:580-6.
13 Nissler K, Von Katte I, Huebner A, et al. Pancreatic elastase 1 in feces of preterm and term infants. J Pediatr Gastroenterol Nutr 2001;33:28-31.

14 Von Seebach I, Henker J. Pancreatic elastase-1 in faeces of preterm and term born infants up to 12 months without insufficiency of exocrine pancreatic function [abstract]. $21^{\text {st }}$ European Cystic Fibrosis Conference, June 1997. Davos, Switzerland.

15 Terbrack K-H, Gurtler G, Huls P, et al. Human fecal pancreatic elastase in children. Monatsschr Kinderheilkd 1996;144:901-5.

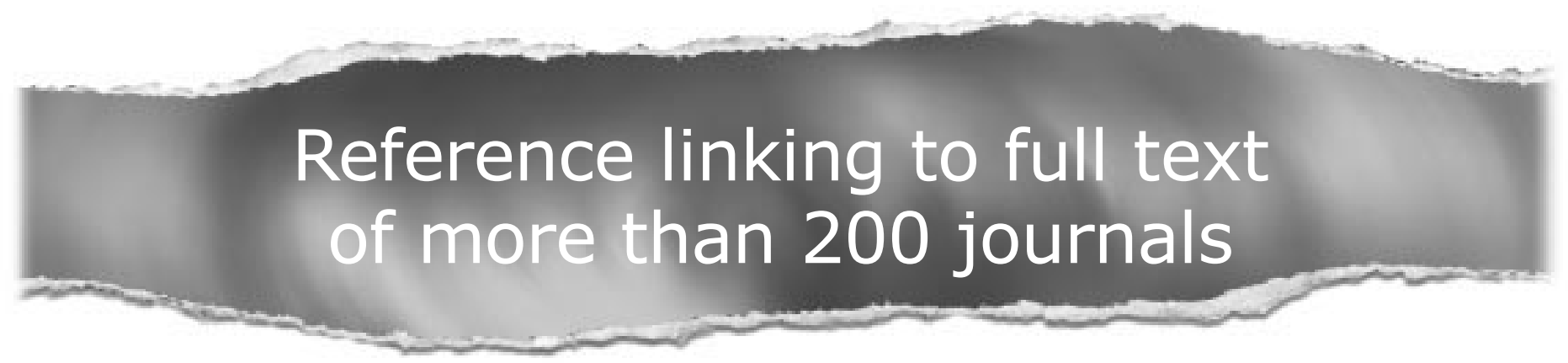

\section{Toll free links}

You can access the FULL TEXT of articles cited in Archives of Disease in Childhood online if the citation is to one of the more than 200 journals hosted by HighWire (http://highwire.stanford.edu) without a subscription to that journal. There are also direct links from references to the Medline abstract for other titles.

www.archdischild.com 